\title{
Participatory Approach versus Bureaucratic 'Pressure': The Case of Health Information Systems Programme
}

\author{
C.R. Ranjini \\ Centre for Public Policy, \\ Indian Institute of Management Bangalore, India \\ ranjini.cr@gmail.com
}

\begin{abstract}
Implementation of Information Systems in Public Healthcare in India has been a very complex undertaking. Participation of the end-users during design and implementation is important. Participation within bureaucratic settings poses unique challenges, due to hierarchical, centralized, authoritarian and formalistic practices. Even where State agencies have experimented to bring in imaginative changes, participation have not been voluntary, but have been enforced. This short paper attempts to analyse less know and less understood aspect of participatory approach entangled within bureaucratic systems. This paper attempts to analyse the issues around participation in order to identify two key areas: [1] How to encourage public sector employees to participate during design, development and implementation of IS? [2] How can public sector institutions encourage effective participation? Discourses on Participatory Approach is drawn upon to analyse the case of Health Information Systems Programme.
\end{abstract}

Keywords: Health Information Systems [HIS], Participation, Public Healthcare, Design, Implementation.

\section{Introduction}

Information and Communication Technologies [ICTs] offer tremendous potential to improve and transform many facets of public healthcare delivery. Yet the reality of ICT projects most often does not match the general optimism surrounding the grand notion of bringing about transformations through the introduction of technology. There are various reports of 'total', 'partial', 'sustainability', and 'replication' failures [Heeks, 2000a]. Projects fail due to 'design-actuality' or 'design-reality' [Heeks, 2003a] gaps, or lack of commitment on the part of the political leadership and public managers [Bhatnagar, 2000].

While Health Information Systems are being actively introduced by international agencies, national and local governments as a part of various health reform efforts, what is often found is that the focus of such efforts is primarily on the means (computerization) rather than the ends, or what needs to be achieved (i.e., strengthening information support for health management) [Ranjini \& Sahay: 2006]. Over the years, research has emphasized that the critical issues to be addressed in the implementation of information systems are social and organisational, not solely technical 
[Anderson \& Aydin, 1997, Walsham, 1993]. Institutionally, HIS in developing countries are situated in rather centralized structures [Braa et al, 2001, Braa, Heywood \& Shung King, 1997] in which local use of information is not encouraged [Opit, 1987].

This article seeks to examine the relationship among participatory practices during the design and implementation of HIS and that of bureaucratic practices, with a view to analyze the potential role of ICTs in furthering the e-governance agenda and how it can be achieved in practice. This question is analyzed based on an examination of the literature around participatory approach in order to identify what makes it problematic to achieve participation in public sector institutions and what can be done about it.

\section{$2 \quad$ Participatory Approach}

Participation of people, end-users and more importantly by beneficiaries/stakeholders themselves has been emphasized during the design and use of ICT projects. Participation is considered a key issue not only for understanding existing capabilities but also for developing new ones among different users [Quraishy and Gregory, 2005]. In Information Systems, participatory design [Kuhn. S \& Muller. M.J, 1993] has been emphasized to duly consider the social context in which the system is to be embedded [Avgerou, 2002], potentially contributing to better designed systems. In Scandinavia, the collective resource approach [Ehn \& Kyng, 1987] emphasized union empowerment, not merely to oppose induction of new technologies [including ICTs], but also to develop innovative ways in which technology could be harnessed in the workplace to further workers' interests through democratic participation [ibid]. Mumford, E [2006a] developed a system design methodology, that she called ETHICS (Effective Technical and Human Implementation of Computer-based Systems) to help design a system primarily from the perspective of the user(s) and advocates that it is paramount that they work closely with developers to specify socio-technical requirements. Users be allowed to change work practices and organizational structures so as to enable the smooth transition of the new system. Participative design is seen as being consultative, democratic and responsible in nature, thus fitting with the ethical stance that individuals have an inherent right to take part in changes that take place within their own work situation.

\section{Case Study: Health Information Systems Programme}

The Health Information Systems Programme [HISP] is a global research and development network initiated in 1994 by researchers in the Department of Informatics, University of Oslo, in collaboration with universities and health authorities in South Africa. The stated goals of HISP [Braa et al, 2004] are to develop an open source, not-for-profit District-based Health Information Software [DHIS], strengthen health information management at district and community levels, assist in local analysis and use of data, conduct training programmes, standardize primary healthcare data and maximize end-user participation. Most distinctively, HISP is committed to a bottom-up design and system development approach to support decentralised health management.

In India, HISP was started in December 2000 in Andhra Pradesh. HISP India sought to strengthen information practices within the primary healthcare sector, with 
the larger aim of improving processes of healthcare delivery for the rural community. The HISP in Andhra Pradesh had the following key aims:

1. To develop a district-focused computer-based health information system;

2. To develop capacity for information management among staff at various levels of the health system; and

3. To integrate the health information system with other ongoing e-governance initiatives in the State.

\subsection{Pilot Phase}

Kuppam, in Chittoor district of Andhra Pradesh was chosen by HISP as a locale offering adequate infrastructural and government support, and also because the area is relatively small. During situational analysis, the HISP team undertook a study of the reporting processes and analysed the existing technological and physical infrastructure. The situational analysis found that health assistants went out into the communities served by their sub-centres and collected data on several health programmes, including some programmes that had long been discontinued by the department! The quality of data was poor and all the data were recorded manually in different registers for different health programmes. Together, these registers contained about 1,500 data elements, all of which were collected by the health assistants and entered manually week after week, month after month. The Health Supervisor at each health centre compiled aggregate reports from the registers obtained from all the health assistants of the sub-centres under the health centre and sent these reports, numbering about 25 , to the District Office every month. Each District Office, in turn, aggregated the reports from all the health centres into district reports and sent them to the State office in Hyderabad, called the office of the Commissioner of Family Welfare.

HISP began its activities by rationalizing and constructing Minimum Data Sets for the sub-centres and health centres. It adopted a participatory approach involving health assistants and staff at the health centres and district office during the construction of these minimum data sets [Puri et al, 2004]. The data sets were subsequently discussed with the Commissioner of Family Welfare, and this effort was aligned with similar efforts at streamlining data sets undertaken by the office of the Commissioner. This was followed by customization of the district health information software package that was originally developed in South Africa to suit the local needs of the health staff in Andhra Pradesh. The software package allowed entry, validation and analysis of routine data of the health service rendered [monthly, quarterly and annually], semipermanent data [population estimates, equipment, and personnel numbers] and survey data. Routine and analysis reports were customized. The HISP software also enabled automatic generation of reports. Computers were installed in six health centres and the minimum data sets and the database were then set up there. Health assistants began to enter the data and generate reports.

HISP trainers were involved in implementing the project. Training health centre staff was an important aspect of the implementation process, and HISP team offered both onsite and off-site training. The content of the training included practical sessions on how to use the software application and generate analysis reports, and lectures on the use of information for local action. 


\subsection{Expansion Phase}

After the pilot phase, the project was extended to 37 health centres in Madanapally, Andhra Pradesh, thus taking the project to 46 health centres in all. In Madanapally, however, a different approach - a hub strategy - was adopted, with one computer serving a cluster of health centres. Twelve health centres with adequate physical infrastructure and facilities were selected as hubs. Trainers were stationed in the twelve hubs. They trained the staff from three or four nearby health centres. The hubs became the location for their regular data entry work and report generation.

Simultaneously, HISP also created a computerised health database for Chittoor district. The database was put together at the district office by manually entering health data from all 84 health centres in Chittoor district into DHIS. A team member did this at the end of each month. HISP also began to integrate routine data with maps, using Geographical Information Systems. The aim was to provide spatially-based information on the health status of the district; for example, with regard to the prevalence of diseases in certain regions. The HISP team was later involved in developing a web interface, and in translating the interface into Telugu, the local language.

\section{Participation versus 'Pressure'}

With reference to above described case study the author attempts to analyse participation from two standpoints: [1] How to encourage public sector employees to participate during design, development and implementation of IS? [2] what is the role of institutions in enabling effective participation.

Influenced by the Scandinavian discourse of Participatory Approach, the HISP focused not just on the development of DHIS, but also involved health workers, doctors and other health staff during the design, development and implementation of the HISP. Participation of the health staff and assistants was essential for HISP as it had adopted an approach committed to bringing about changes from the grassroots level, at sub-centres and health centres. However, in order to introduce new ways of working and change the existing practices at the sub-centres and health centres, participation of the health staff had to be facilitated by the district and State officials. Only when they received instructions from their higher officials did the staff at the health centres and sub-centres participate in these activities. When I asked Prof Sundeep Sahay, who had initiated the HISP programme in Andhra Pradesh, to what extent the health assistants had participated in the design of HISP software and how the health staff had participated in the implementation, he said:

It has been very different from the way it has been done in Scandinavia... It is not that they, health assistants have said they want the system. We have gone with the system. We have gone to Kuppam because the Chief Minister asked us to go to Kuppam. In that sense, the decisions were taken very much from the top.

However, he added that health assistants participated during the system development process and particularly during the creation of the minimum data sets. Health assistants regularly collected about 1,500 data elements for different health programmes. The HISP team adopted a participatory approach, involving health assistants, to 
rationalise the data set. This effort resulted in eliminating redundancies and construction of a minimum data set with about 400 elements [Ranjini \& Sahay, 2006]. Prof Sahay explained:

During the creation of the minimum data sets we got together all the forms and data items from sub-centres and health centres and gave them to the health assistants and asked them to use this form to collect the data. Then the next month, the HISP team went and saw what data had been collected and what problems they have had. This process was repeated three or four times. Then we had a workshop. There were some 70-80 people. We created small heterogeneous groups of doctors and health assistants. We gave them the forms we had re-designed and asked them to comment on them. We got lots of comments on that day. Then we sat with the district officer in the evening. We went through all the suggestions people had made and the district officer gave his comments on what should be accepted and what should not. Then we created new set of forms and I went to Hyderabad [the State capital] with that... The Commissioner then made more changes... It was quite an interactive process at different levels. From health assistants to... the Commissioner.

Achieving local participation, although not impossible, is extremely difficult in practice, particularly in a bureaucratic organisation such as the Family Welfare Department. This is because work activities within government organisations are tied to rigid hierarchical structures, strong adherence to complicated rules, procedures and norms, differential power relations and frequent delays. Besides these institutional constraints, there is also corruption. This environment undermines local innovation based on the reflection and learning.

A recurring theme that emerged during my discussion with trainers was that of 'pressure'. HISP trainers felt that to initiate these changes at the grassroots, a push from the top was necessary. Attempts to institutionalise these new systems resulted in putting pressure on the end-users to participate and to learn. Quraishy and Gregory [2005] recall that during the initial stages of HISP: "A majority of health staff, mostly women and those working at the community level, attended the training programme... they participated in the training programme because there was pressure from their immediate superiors, the District Manager and Health Officer at the district and the Special Officer at the constituency level." HISP trainers also admitted that health assistants attended classes only because of the pressure from the Special Officer. The HISP trainers saw the strategy of applying pressure as necessary for sustaining the project. One trainer said: "The project will be successful only if there is pressure from higher authorities. Only if it is made compulsory will the whole exercise be useful." Higher authorities had to be involved in encouraging as well as enforcing participation of health assistants during the development of the system as well as during its adoption into use. However, one doctor was critical of HISP's approach and commented: "They brought in a lot of pressure from higher officers. There was pressure from the Special Officer. Out of fear they (health assistants) have learnt computers. That has added to our stress."

That is, unless there was pressure from the higher officials to regularly enter data or to generate computerised reports or to attend computer training, the health assistants, supervisors and doctors did not participate in the project. There was pressure also because it was the then Chief Minister's political constituency and the performance and implementation of projects were regularly monitored. To a certain extent 
health assistants did yield to these pressures and began data entry. However, supervisors and doctors resisted these kinds of pressures during the stage of data collation and report generation. A system developer said that the supervisors and doctors resisted using the HISP system to generate health reports [Ranjini.C.R: 2007]. He commented:

I think the direction has to come directly from the top to generate these [computerized] reports. Until then it won't happen. Now a trainer is going, and because of him everyone is entering data. Everything must be institutionalised. Only then health staff will generate the reports.

Puri et al [2004:48] in a paper on user participation in HISP's Andhra project write:

The course of health informatics in India has been strongly influenced by differential power relations arising from rigid hierarchical structures and strong bureaucracy. In starkly different historical, political and social contexts such as India, participatory processes will not arise naturally as a result of democratic aspirations or reasoned argumentation, as may be the assumption in formal workplace settings of Western countries like Scandinavia or the UK. Paradoxically, however, participatory processes often need to be initiated by government officials in-charge, rather than these emerging idealistically from grassroots as a bottom-up process... and then be gradually nurtured over time.

In such a scenario, How can public sector institutions encourage effective participation? Mumford [2006a] advocates: "Participation can take many forms but at the lower levels it is increasingly concerned with the relationship between individuals and their work environment. It must be stressed, however, that if employees are to be able to exercise some control over this then they need opportunity, confidence and competence and methods for achieving this need careful thought. One prerequisite for a participatory community... is the development of some shared values and objectives concerning participation." But an approach primarily focused on building grassroot level participation, without the permission from the top, would arguably end in a failure in the Indian context [Braa \& Sahay, 2012].

In the case of HISP, the Family Welfare Department could have individually as well as collectively encouraged participation both through in-house training activities, during monthly meetings as well as official visits by officers. Internet and mobile technology can be innovately harnessed to enroll participation of staff, even in remote area. It can be suggested that participation at different levels is necessary and that it should be ongoing during implementation leading to instituitonalisation. Institutionalisation can be seen as necessary for the sustainability of information systems. Silva and Backhouse [1997:390] characterise stabilisation of an information system as institutionalisation: "Information systems become institutionalised when they are no longer considered as innovations, but as unnoticed and unremarkable tools that people take for granted in doing their work." That is, use of analytical reports or schedules or reporting through health information systems can be possible in practice only if it is institutionalised over time through official procedures and practices. Institutionalisation, arguably becomes a necessity for sustaining information systems, but the challenge is to involve the health staff by encouraging participation, rather than coercion. 


\section{Conclusion}

One of the main reasons for the failure of HISP in Andhra Pradesh was that top bureaucracy was only partially involved in this initiative. Even today, most of public sector e-governance projects, initiated by different government departments do not encourage individual and collective participation by heterogeneous groups of employees. In bureaucratic settings, neither top-down nor bottom-up approaches succeed. There need to be an integrated participation effort, where-in both officials at the top and staff at the bottom of the hierarchy are enrolled. Continuous participation from a heterogeneous group has to be attempted, not through pressure and coercion, instead by facilitating 'genuine' participation. For Simonsen and Robertson (2012) 'genuine' participation, refers to the fundamental transcendence of the users' role from being merely informants to being legitimate and acknowledged participants in the design process. Further, this role is established - for example - when users are not just answering questions in an interview about their point of view or knowledge of a particular issue, but are asked to step up, take the pen in hand, stand in front of the large whiteboard together with fellow colleagues and designers, and participate in drawing and sketching how the work process unfolds as seen from their perspective. This is a big challenge both for leaders and employees in public sector.

\section{References}

Anderson, J.G., And Aydin, C.E.: Evaluating The Impact Of Health Care Information Systems. International Journal of Technology Assessment in Health Care 13(2), 380-393 (1997)

Avgerou, C.: Information systems and global diversity. Oxford University Press, New York (2002)

Avgerou, C., And Walsham, G.: Introduction: IT in Developing Countries in Information Technology In Context. In: Studies from the Perspective of Developing Countries. Aldershot, Ashgate (2000)

Braa, J., et al.: A Study Of The Actual And Potential Usage Of Information And Communication Technology at District And Provincial Levels In Mozambique With A Focus On The Health Sector. Electronic Journal In Information Systems For Developing Countries 5(2), 1-29 (2001)

Braa, J., Heywood, A., Shung King, M.: District Level Information Systems: Two Cases From South Africa. Methods Of Information In Medicine 36(2), 115-121 (1997)

Braa, J., Monteiro, E., Sahay, S.: Networks of Action: Sustainable Health Information Systems Across Developing Countries. Management Information Systems Quarterly 28(3) (2004)

Braa, J., Sahay, S.: Integrated Health Information Architecture, Power to the Users. Matrix Publishers, New Delhi (2012)

Beck, E.E.: On Participatory Design in Scandinavian Computing Research. Department of Informatics, University of Oslo (2001)

Bhatnagar, S.C.: Information Technology in Development Communication: Key Issues. In: Bhatnagar, S.C., Schware, R. (eds.) Information \& Communication Technology in Development Communication: Cases from India, pp. 17-31. Sage Publications India Pvt Ltd., New Delhi (2000) 
Ehn, P., Kyng, M.: The Collective Resource Approach to Systems Design. In: Bjerknes, G., Ehn, P., Kyng, M. (eds.) Computers and Democracy-A Scandinavian Challenge, pp. 17-57. Avebury, Aldershot (1987)

Heeks, R.: Information Technology, Information Systems and Public Sector Accountability. In: Avgerou, C., Walsham, G. (eds.) Information Technology In Context. Studies From The Perspective Of Developing Countries. Ashgate, Aldershot (2000a)

Heeks, R.: Most E-government-For-Development Projects Fail: How Can Risks Be Reduced. IDPM I-Government Working Paper No.14 (2003a)

Kappelman, L., McLean, E.: The Respective Roles of User Participation and User Involvement in Information System Implementation Success. In: DeGroass, J.L., Benbasat, I., DeSanctis, G., Beath, C.M. (eds.) Proceedings of the Twelfth International Conference on Information Systems, New York, pp. 339-349 (1991)

Kling, W, S.: The Web of Computing: Computer technology as social organization. In: Yovits, M.C. (ed.) Advances in Computers, vol. 21, pp. 1-90 (1982)

Kuhn, S., Muller, M.J.: Participatory Design. Communications of the ACM 36(4), 24-28 (1993)

Mumford, E.: Designing Human Systems for New Technology - The ETHICS Method, Manchester Business School, Manchester, U.K (1983)

Mumford, E.: The Ethics Method (2006a), http: / /www. enid.u-net.com/index.htm (last visited March 14, 2013)

Opit, L.J.: How Should Information On Healthcare Be Generated And Used? World Health Forum (8), 409-438 (1987)

Puri, S.K., Byrne, E., Leopoldo, J., Quraishi, Z.B.: Contextuality Of Participation In IS Design: A Developing Country Perspective. In: Paper Presented At The Participatory Design Conference, Toronto, Canada (2004)

Quraishy, Z., Gregory, J.: Implications Of (Non) Participation Of Users In Implementation Of The Health Information System Project (HISP) In Andhra Pradesh: Practical Experiences. In: Proceedings Of The 8th International Working Conference of IFIP WG 9.4, Enhancing Human Resource Development Through ICT, Abuja (2005)

Ranjini, Sahay: Computer-Based Health Information Systems - Projects for Computerization or Health Management?: Empirical Experiences from India. In: Gascó-Hernández, M., EquizaLópez, F., Acevedo-Ruiz, M. (eds.) Information Communication Technologies and Human Development: Opportunities and Challenges, Idea Group Inc. (2006)

Ranjini, C.R.: Towards Building and Implementing Public Health Information Infrastructures: An Ethnographic Study in India, unpublished PhD dissertation, Department of Sociology, Lancaster University (2007)

Silva, L., Backhouse, J.: Becoming Part of The Furniture: The Institutionalization Of Information Systems. In: Lee, A.S., Liebenau, J., Degross, J.I. (eds.) Information Systems And Qualitative Research, pp. 389-413. Chapman and Hall, London (1997)

Simonsen, J., Robertson, T. (eds.): Routledge International Handbook of Participatory Design. Routledge, New York (2012)

Walsham, G.: Interpreting Information Systems in Organizations. John Wiley and Sons Ltd., Chichester (1993) 